\title{
Effects of Friction Plate Hardness and Surface Orientation on the Frictional Properties of Cereal Grain
}

\author{
Zdzisław Kaliniewicz $\mathbb{D}^{1},{ }^{1}$ Krzysztof Jadwisieńczak $\mathbb{D}^{1},{ }^{1}$ Zbigniew Żuk, $^{1}$ Stanisław Konopka, \\ Adam Frączyk $\left(\mathbb{0},{ }^{1}\right.$ and Zbigniew Krzysiak $\left(\mathbb{1}^{2}\right.$ \\ ${ }^{1}$ Faculty of Technical Sciences, University of Warmia and Mazury in Olsztyn, Olsztyn 10-719, Poland \\ ${ }^{2}$ Department of Mechanical Engineering and Automation, University of Life Sciences in Lublin, Lublin 20-612, Poland \\ Correspondence should be addressed to Zdzisław Kaliniewicz; zdzislaw.kaliniewicz@uwm.edu.pl
}

Received 12 October 2020; Revised 3 November 2020; Accepted 6 November 2020; Published 16 November 2020

Academic Editor: Carl J. Schaschke

Copyright (C) 2020 Zdzisław Kaliniewicz et al. This is an open access article distributed under the Creative Commons Attribution License, which permits unrestricted use, distribution, and reproduction in any medium, provided the original work is properly cited.

\begin{abstract}
The objective of this study was to evaluate the effects of the friction plate hardness and surface orientation of a friction plate on the angle and coefficient of static friction of cereal kernels. The angle of static friction of kernels representing four major cereal species was measured on six friction plates with different hardness. The friction plates were placed in position where their surface orientation was perpendicular or parallel relative to their inclination tilt. The experimental material comprised the so-called flat seed units, where each unit consisted of three spaced kernels. The angle of static friction of every flat seed unit was measured with a dedicated device in three replications, and average values of that angle were calculated. The kernels' angle of static friction varied considerably from $13^{\circ}$ to $33^{\circ}$ within the analyzed range of changes in the surface characteristics of friction plates. The average angle of static friction was influenced mainly by the surface orientation of the friction plate that came into contact with cereal kernels. The angle of static friction was $17.5 \%$ to $56.5 \%$ higher when the friction plate had perpendicular rather than parallel surface orientation. The frictional properties of kernels were less influenced by plate hardness, and clear relationships were not observed in this respect. The kernels' coefficient of static friction remained fairly constant within the analyzed range of plate hardness values, and it was estimated at 0.4 on plates with a perpendicular surface orientation and at 0.3 on plates with a parallel surface orientation.
\end{abstract}

\section{Introduction}

Cereal grain is widely used in the production of food and feed on account of its high starch and protein content. It is an important raw material in numerous industries, in particular in the production of flour, grits, breakfast cereals, alcoholic beverages, and pharmaceutical products. The properties of cereal grain and the variations and correlations between those traits have to be researched to optimize food and feed production processes. The frictional properties of grain should also be investigated to improve seed movement characteristics in processes where grain is transported [1-3].

Friction leads to the dissipation of energy during the mutual displacement of two objects in contact. These objects have uneven surfaces that tug on each other, causing deformation and wear $[2,4]$.
Numerous theories have been developed to explain selected aspects of friction which is a highly complex process [4]. The theory developed by Frączek [1] proposed a detailed and comprehensive procedure for describing the friction phenomena in biological granular material. According to Frączek and other authors [1-4], friction combines three interconnected forces: deformation, adhesion, and cohesion, where adhesion plays a major role in biological granular materials. Frączek [1] concluded that friction is difficult to interpret because it is influenced by the properties of materials that come into mutual contact, contact time, including surface roughness, the real area of contact, and seed hardness. Similar definitions of friction have been proposed by other authors, including Molenda and Horabik [5], Afzalinia and Roberge [2], Baum et al. [6], Popov [4], and Weber et al. [7]. 
Frączek [1] postulated that the frictional properties of seeds are determined by the geometric structure of the friction plate and the surface roughness of plant materials. According to Kaliniewicz and Żuk [8] and Kaliniewicz et al. [9], certain plate roughness values can contribute to a considerable increase in the coefficient of friction of cereal grains, which can be attributed to adhesive contact between the kernel surface and the plate surface asperities. The adhesion is lowest when surface roughness approximates $\mathrm{Ra}=0.9 \mu \mathrm{m}$. Therefore, the surface roughness of machines and devices that come into contact with the transported grain should approximate the above value. However, the influence of a friction plate's surface orientation and hardness on the frictional properties of seeds has not been investigated to date. Plate hardness does not appear to exert a practically significant effect on the hardness of cereal kernels $[1,4]$, but seed transport operations lead to surface abrasion in the long term. This observation could suggest that the hardness of structural materials can significantly influence the frictional properties of seeds.

The objective of this study was to evaluate the impact of the hardness and surface orientation of a steel friction plate on the angle and coefficient of static friction of kernels and to provide data for modeling and conducting grain processing operations.

\section{Materials and Methods}

2.1. Preparation of Steel Plate Specimens. Seeds undergo numerous processing operations between harvest and sowing or processing, and they come into contact with the structural elements of processing equipment. The components of most seed processing machines are made of steel alloys with different hardness characteristics. In this study, the analyzed plates were made of $41 \mathrm{Cr} 4$ steel whose strength parameters can be controlled and modified through heat treatment. Therefore, six samples measuring $50 \times 30 \mathrm{~mm}$ each were cut out from a rolled steel sheet with a thickness of $5 \mathrm{~mm}$. The samples were placed in the Nabertherm LH15/114 chamber furnace (Nabertherm GmbH Lilienthal, Germany) and were austenized at a temperature of $850^{\circ} \mathrm{C}$ for 10 minutes. The austenized samples were hardened by immersion in water until they were completely cooled. One sample was set aside, and the remaining samples were tempered at different temperatures $\left(200^{\circ} \mathrm{C}, 300^{\circ} \mathrm{C}, 400^{\circ} \mathrm{C}, 500^{\circ} \mathrm{C}\right.$, and $\left.600^{\circ} \mathrm{C}\right)$ in an electric furnace for 1 hour. The tempered samples were immersed in water until they were completely cooled. Each sample was ground on one side with the SPC 20b surface grinder (PPHU Metalex Jarosław Kucharski, Bydgoszcz, Poland) to obtain samples with similar surface roughness and to remove carbonized material. A grinding disc with a diameter of $250 \mathrm{~mm}$ and thickness of $25 \mathrm{~mm}$ was used (38A $60 \mathrm{KVBE}$ ). The samples were ground along the longer side to a cutting depth of $0.02 \mathrm{~mm}$. Hardness was measured with the HPO 250 hardness tester (WPM Leipzig, Germany) at three randomly selected points on the ground surface at $300 \mathrm{~N}$ (HV30) load. Surface roughness was determined with the Diavite DH-5 surface roughness meter (Diavite AG Bülach, Switzerland) by measuring parameter Ra in a direction paral-

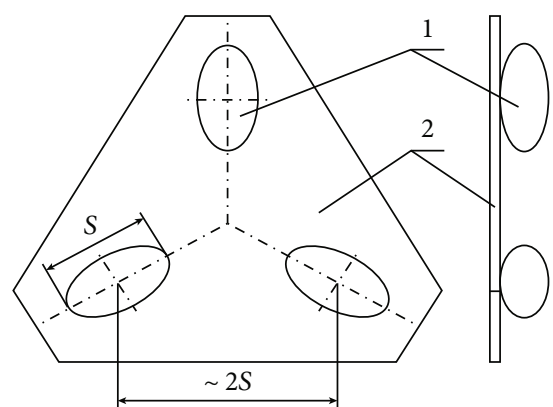

FIGURE 1: Flat seed unit [9]: 1: seed; 2: adhesive tape; $S$ : seed dimension.

lel and perpendicular to the surface orientation. The measurements were conducted in three replicates. The samples were used as friction plates to measure the angle of static friction of kernels. After the measurements, metallographic specimens were cut out from plate cross-sections and were used to describe the crystal structure of each phase. The specimens were ground with abrasive paper with increasing grit size: P100, P150, P220, P280, P320, and P600, and they were polished with DiaoDuo diamond suspension and MD Largo, MD Dac, and MD Chem discs (Struers A/S Ballerup, Denmark). The resulting surfaces were digested with $3 \%$ nitric acid, and the exposed microstructure was analyzed under the Olympus IX M light microscope (Olympus Corporation, Tokyo, Japan) at 400x magnification.

2.2. Preparation of Seed Samples. The experimental material comprised kernels of four major cereal species and cultivars that are widely grown in Poland: barley cv. Irina, oats cv. Komfort, rye cv. Dańkowskie Granat, and wheat cv. Artist. The grain of every cereal species was harvested in 2017 with a combined harvester in the northern Poland region. To achieve and maintain the desired moisture content, preliminary grain samples of $2 \mathrm{~kg}$ each were uniformly spread in containers and stored for 2 months in a closed compartment at a constant temperature of around $22^{\circ} \mathrm{C}$. After storage, 50 seeds of each cereal species were selected by survey sampling. The physical properties of seeds, including basic dimensions and mass, were determined. In each of the 12 experimental variants ( 6 hardness variants $\times 2$ surface orientation variants), 50 flat seed units (Figure 1) were used to determine the angle of static friction. A flat seed unit consisted of seeds placed crease down on the friction plate. The three seeds in each flat seed unit were spread out, and the geometric center of each unit was localized at the vertex of an equilateral triangle with side length equivalent to around two average seed lengths. The seeds were combined with adhesive tape. Three seed samples of $200 \mathrm{~g}$ each were obtained from the remaining bulk of each cereal species for moisture content analysis.

2.3. Physical Properties of Kernels. The geometric properties and the mass of cereal kernels were specified according to the method proposed by Kaliniewicz and Żuk [8]. Kernel length $L$ and kernel width $W$ were gauged using a workshop microscope (MWM 2325, PZO Warszawa, Poland; resolution: $0.01 \mathrm{~mm}$ ). Kernel thickness $T$ was measured with a dial 

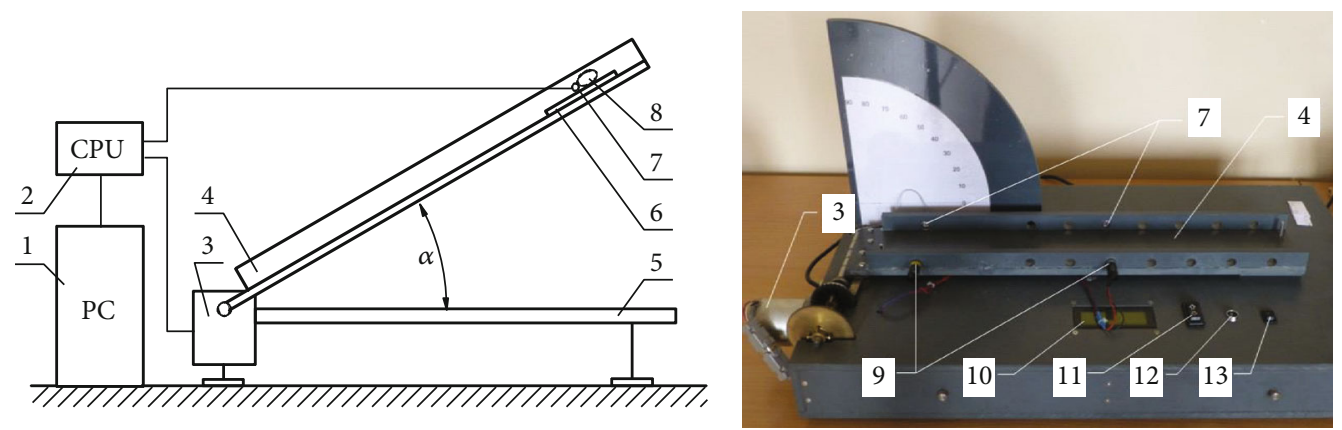

FIGURE 2: Test stand for measuring the external friction angle of seeds: 1: computer; 2: CPU (central processing unit) converter; 3: stepper motor lifting the arm of the instrument; 4: arm; 5: base of the instrument; 6: friction plate; 7: light receiver; 8: seed; 9: light emitter; 10: LSD display; 11: switch for manually controlling the arm of the instrument; 12: status diode light (on or off); 13: main on/off switch.

indicator thickness gauge (MasterTools, Cracow, Poland; resolution: $0.01 \mathrm{~mm}$ ). Kernel mass was measured to the nearest $0.1 \mathrm{mg}$ on a weighing scale (WAA 100/C/2, Radwag Radom, Poland). The indicators (aspect ratio $R$, geometric mean diameter $D$, and sphericity index $\Phi$ ) of every seed were calculated using known formulas [9].

The angle of static friction $\gamma$ of kernels was measured with a test instrument (Figure 2) equipped with photosensors [8-10]. Friction plates made of $41 \mathrm{Cr} 4$ steel were mounted on an adjustable arm of the above instrument near the photosensor. The plates were arranged in two positions: with the surface orientation parallel and perpendicular relative to their inclination tilt, i.e., in the direction of the motion of the flat seed unit. The measurement began by placing the arm of the instrument in a horizontal position. Every flat seed unit was placed directly above the light beam emitted by the optical system, and its tip was oriented downward the friction plate. The instrument was activated, and the angle of the adjustable arm was gradually changed until the flat seed unit was set into motion and the light beam was interrupted. The adjustable arm was paused, and its angle was read with a precision of $0.01^{\circ}$. Each flat seed unit was gauged in three replicates, and mean values were calculated. After each series of measurements conducted on 5 flat seed units, the surface of the friction plate was wiped with a cotton swab damped in petroleum ether to remove cutin residues.

The coefficient of static friction $\mu$ of every seed in the tested positions relative to the surface orientation of the friction plate was calculated with the use of the below formula [4]:

$$
\mu=\tan \gamma
$$

The relative moisture content of grain was measured with a halogen moisture analyzer fitted (MAX 5-/WH, Radwag Radom, Poland).

2.4. Statistical Analysis. The measured angles of static friction were analyzed using Statistica Pl v. 13.3 software (StatSoft Polska Sp. z o.o., Kraków, Poland). Differences in the measured values were determined by ANOVA based on the results of the Shapiro-Wilk $W$ test, Levene's test, and
TABLE 1: Hardness and surface roughness of friction plates (mean value \pm standard deviation).

\begin{tabular}{lcccc}
\hline $\begin{array}{l}\text { Plate } \\
\text { no. }\end{array}$ & $\begin{array}{c}\text { Tempering } \\
\text { temperature }\left({ }^{\circ} \mathrm{C}\right)\end{array}$ & $\begin{array}{c}\text { Hardness } \\
\text { HV30 }\end{array}$ & \multicolumn{2}{c}{$\begin{array}{c}\text { Surface roughness Ra }(\mu \mathrm{m}) \\
\text { of plates with different } \\
\text { surface orientations } \\
\text { Parallel }\end{array}$} \\
\hline 1 & - & $655 \pm 14$ & $0.61 \pm 0.02$ & $1.39 \pm 0.04$ \\
2 & 200 & $611 \pm 12$ & $1.70 \pm 0.05$ & $2.87 \pm 0.03$ \\
3 & 300 & $554 \pm 22$ & $0.94 \pm 0.03$ & $2.48 \pm 0.06$ \\
4 & 400 & $478 \pm 5$ & $1.26 \pm 0.04$ & $2.52 \pm 0.04$ \\
5 & 500 & $380 \pm 6$ & $0.26 \pm 0.01$ & $0.62 \pm 0.02$ \\
6 & 600 & $311 \pm 4$ & $0.58 \pm 0.02$ & $0.59 \pm 0.02$ \\
\hline
\end{tabular}

Duncan's test. The results were regarded as significant at $\alpha=0.05$.

\section{Results and Discussion}

3.1. Friction Plates. According to Standard ISO 683-2:2016 [11], the structural material with symbol $41 \mathrm{Cr} 4$ is alloy chrome steel for quenching and tempering which is characterized by moderate hardenability and is recommended for the production of machine parts with a thickness of up to $40 \mathrm{~mm}$. This alloy steel has a hardness of $240 \mathrm{HB}$ in the soft annealed state and maximum hardness of $65 \mathrm{HRC}$ in the hardened state [12]. Alloy steel with a sorbite structure has enhanced mechanical and fatigue performance. Sorbite is a structural component which is obtained by tempering martensite. Tempered martensite undergoes structural transformation, and it is composed of globular grains of cementite embedded in ferrite. Sorbite is produced by hardening and high-temperature tempering. Tempering improves the structural and mechanical properties of heat-treated materials, depending on the applied temperature and cooling method $[13,14]$. The data presented in Table 1 confirm the above correlation. Tempering temperature is selected to obtain the desired material hardness, and the higher the temperature, the lower the hardness of the processed material. The highest hardness $(655 \mathrm{HV})$ was noted in the sample that was subjected to hardening only. A microstructural analysis 


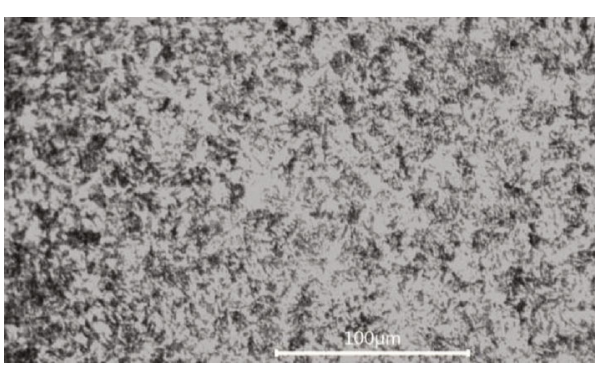

(a)

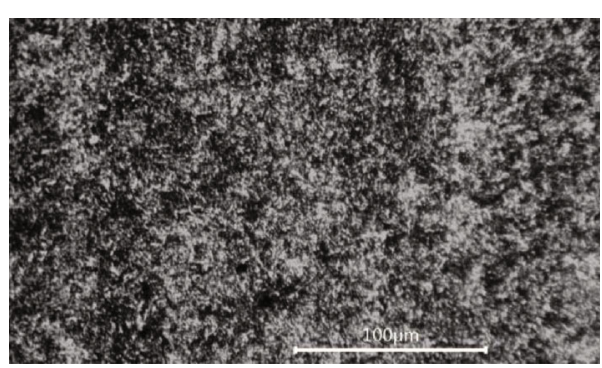

(b)

Figure 3: Microstructure of hardened $41 \mathrm{Cr} 4$ steel (400x magnification): (a) without tempering; (b) after tempering at a temperature of $500^{\circ} \mathrm{C}$.

(Figure 3(a)) revealed the presence of fine lamellar martensite with retained austenite. Tempering at increasing temperatures (Figure 3(b)) did not induce microstructural changes that could be clearly discerned under an optical microscope, but hardness was considerably reduced to $311 \mathrm{HV}$. Changes in hardness are associated with the dispersion and coagulation of carbides, which decreases the content of carbon in martensite and transforms retained austenite into bainiticsorbitic structures. The above effects could be observed under a scanning electron microscope at a magnification of up to several thousand times. The correlation between tempering temperature and steel hardness (HV) was best described by a quadratic polynomial (Figure 4) where the coefficient of determination was very high at 0.987 .

The roughness of the analyzed friction plates varied considerably despite the application of the same processing method and processing parameters. Surface roughness Ra ranged from 0.26 to 2.87 , and it was highest in the sample tempered at a temperature of $200^{\circ} \mathrm{C}$. In $41 \mathrm{Cr} 4$ steel, surface roughness can be modified not only by grinding but also by optimizing turning parameters for round elements [15]. The correlation between surface roughness and tempering temperature after hardening could not be determined. Significant variations in roughness were noted when measurements were performed in different directions relative to the steel plate's surface orientation. Roughness values were higher when measurements were performed perpendicular to the plate's surface orientation, and in most cases (excluding the sample tempered at a temperature of $600^{\circ} \mathrm{C}$ ), they were more than twice higher. The above can probably be attributed to the presence of grooves machined in the steel plate by the grinding disc and the fact that the asperities formed perpendicular to the direction of motion had a much higher amplitude value than the asperities formed in the parallel direction.

3.2. Cereal Kernels. The physical properties of cereal kernels are shown in Table 2. The examined kernels were characterized by similar relative moisture content of $9.6-9.9 \%$, and they could be stored for prolonged periods without viability loss [16]. Based on the average mass, barley was characterized by the heaviest kernels, and rye was characterized by the lightest kernels. Based on the average length values, oat kernels were longest whereas wheat kernels were shortest. The minimum and maximum values of the shape indicators (aspect ratio and sphericity index) were noted in oat and

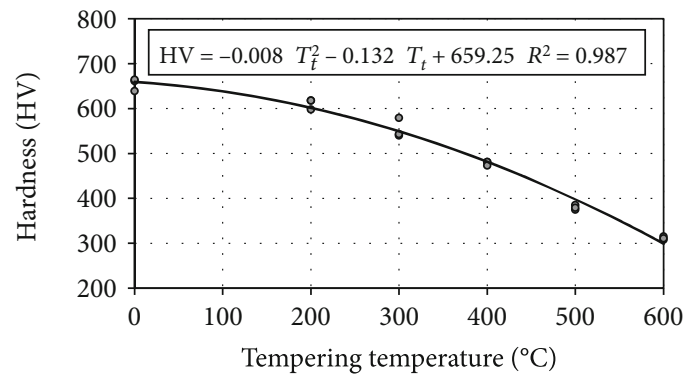

FIgURE 4: The effect of tempering temperature $\left(T_{t}\right)$ on the hardness $(\mathrm{HV})$ of a friction plate made of $41 \mathrm{Cr} 4$ steel (hardness was measured at three points at each temperature).

wheat kernels. The dimensions and mass of the tested kernels and the calculated aspect ratios were similar to the average values reported in the literature $[9,17-20]$.

3.3. Frictional Properties of Cereal Kernels. The angle of static friction (Table 3) of cereal kernels differed considerably from $13.0^{\circ}$ (wheat and triticale kernels on a steel plate with hardness $380 \mathrm{HV}$ and parallel surface orientation) to $33.0^{\circ}$ (wheat kernels on a steel plate with hardness $655 \mathrm{HV}$ and perpendicular surface orientation). According to Frączek [1], the surface asperity patterns are determined by cereal species and variety, and they can differ among individual kernels. As demonstrated by Królczyk [21], different kernel segments are characterized by different surface roughness. The above observation can be used to explain the observed variations in the angle of static friction of cereal kernels on the same friction plate. These differences are not associated with the mass of flat seed units because previous studies (Kaliniewicz [22], Kaliniewicz et al. [10]) have demonstrated that the mass of cereal kernels does not exert a significant effect on their frictional properties. The average angle of static friction differed considerably from $15.4^{\circ}$ (wheat, hardness $655 \mathrm{HV}$, parallel orientation) to $24.1^{\circ}$ (wheat, hardness $655 \mathrm{HV}$, perpendicular orientation). The angle of static friction was largely influenced by the plate's surface orientation, and the average value of this parameter was considerably higher when kernel motion was initiated on a steel plate with perpendicular rather than parallel surface orientation. The measured angles of static friction differed from 17.5\% (barley, hardness $611 \mathrm{HV}$ ) to $56.5 \%$ (wheat, hardness $655 \mathrm{HV}$ ), and all of the noted differences were statistically significant. The 
TABLE 2: Physical parameters of the analyzed kernels (mean value \pm standard deviation).

\begin{tabular}{|c|c|c|c|c|}
\hline \multirow{2}{*}{ Physical parameter ${ }^{\mathrm{a}}$} & \multicolumn{4}{|c|}{ Cereal species } \\
\hline & Barley & Oats & Rye & Wheat \\
\hline Moisture (\% dry basis) & $9.9 \pm 0.03$ & $9.8 \pm 0.02$ & $9.7 \pm 0.03$ & $9.6 \pm 0.04$ \\
\hline Thickness (mm) & $3.2 \pm 0.20$ & $2.6 \pm 0.24$ & $2.7 \pm 0.21$ & $3.1 \pm 0.33$ \\
\hline Width (mm) & $3.9 \pm 0.32$ & $3.2 \pm 0.24$ & $2.9 \pm 0.25$ & $3.4 \pm 0.50$ \\
\hline Length (mm) & $8.4 \pm 0.90$ & $11.8 \pm 1.59$ & $8.0 \pm 0.63$ & $6.8 \pm 0.45$ \\
\hline Mass (mg) & $56.2 \pm 5.63$ & $50.7 \pm 10.60$ & $41.5 \pm 7.44$ & $50.2 \pm 14.93$ \\
\hline Geom. mean diameter $(\mathrm{mm})$ & $4.7 \pm 0.28$ & $4.7 \pm 0.37$ & $3.9 \pm 0.26$ & $4.1 \pm 0.41$ \\
\hline Aspect ratio (\%) & $47.8 \pm 10.18$ & $28.0 \pm 2.96$ & $35.6 \pm 3.38$ & $50.2 \pm 5.66$ \\
\hline Sphericity index (\%) & $56.3 \pm 7.05$ & $40.3 \pm 2.80$ & $49.1 \pm 2.60$ & $61.2 \pm 3.46$ \\
\hline
\end{tabular}

${ }^{\mathrm{a}} \mathrm{Mc}$ values are based on three replications. The remaining parameters are based on 50 replications.

TABLE 3: The angle of static friction of cereal kernels and the significance of differences in angle values.

\begin{tabular}{|c|c|c|c|c|c|c|c|}
\hline \multirow[t]{2}{*}{$\begin{array}{l}\text { Cereal } \\
\text { species }\end{array}$} & \multirow[t]{2}{*}{$\begin{array}{l}\text { Plate } \\
\text { hardness } \\
\text { HV30 }\end{array}$} & \multicolumn{6}{|c|}{$\begin{array}{c}\text { Angle of static friction }\left({ }^{\circ}\right) \text { of cereal kernels } \\
\text { on plates with different surface orientations } \\
\text { Parallel }\end{array}$} \\
\hline & & $\min$. & $\max$. & Average & $\min$. & $\max$. & Average \\
\hline \multirow{6}{*}{ Barley } & 311 & 13.3 & 20.7 & $16.9^{\mathrm{aAB}}$ & 20.0 & 27.3 & $23.5^{\mathrm{bC}}$ \\
\hline & 380 & 14.3 & 18.7 & $16.2^{\mathrm{aA}}$ & 19.0 & 25.3 & $22.0^{\mathrm{bB}}$ \\
\hline & 478 & 15.0 & 23.0 & $17.3^{\mathrm{aBC}}$ & 17.7 & 23.7 & $21.1^{\mathrm{bA}}$ \\
\hline & 554 & 14.3 & 24.0 & $16.6^{\mathrm{aA}}$ & 17.0 & 28.7 & $20.8^{\mathrm{bA}}$ \\
\hline & 611 & 14.7 & 26.3 & $17.7^{\mathrm{aC}}$ & 16.7 & 26.0 & $20.8^{\mathrm{bA}}$ \\
\hline & 655 & 14.7 & 20.0 & $16.3^{\mathrm{aA}}$ & 18.0 & 26.7 & $21.3^{\mathrm{bA}}$ \\
\hline \multirow{6}{*}{ Oats } & 311 & 13.7 & 18.7 & $16.4^{\mathrm{aA}}$ & 17.7 & 26.3 & $22.7^{\mathrm{bAB}}$ \\
\hline & 380 & 14.0 & 19.7 & $16.1^{\mathrm{aA}}$ & 19.7 & 27.7 & $23.0^{\mathrm{bB}}$ \\
\hline & 478 & 15.0 & 20.7 & $17.2^{\mathrm{aB}}$ & 17.7 & 27.0 & $22.0^{\mathrm{bA}}$ \\
\hline & 554 & 13.7 & 28.0 & $17.4^{\mathrm{aBC}}$ & 18.7 & 27.0 & $22.1^{\mathrm{bAB}}$ \\
\hline & 611 & 15.3 & 23.0 & $18.1^{\mathrm{aC}}$ & 19.3 & 34.3 & $22.3^{\mathrm{bAB}}$ \\
\hline & 655 & 14.0 & 25.7 & $17.4^{\mathrm{aBC}}$ & 19.3 & 31.7 & $22.2^{\mathrm{bAB}}$ \\
\hline \multirow{6}{*}{ Rye } & 311 & 13.7 & 20.3 & $17.6^{\mathrm{aD}}$ & 20.7 & 28.3 & $23.4^{\mathrm{bD}}$ \\
\hline & 380 & 14.7 & 21.7 & $16.9^{\mathrm{aC}}$ & 18.3 & 26.3 & $22.1^{\mathrm{bC}}$ \\
\hline & 478 & 14.3 & 22.7 & $16.6^{\mathrm{aBC}}$ & 18.0 & 24.7 & $20.8^{\mathrm{bAB}}$ \\
\hline & 554 & 13.3 & 23.7 & $16.1^{\mathrm{aAB}}$ & 18.3 & 25.3 & $20.6^{\mathrm{bAB}}$ \\
\hline & 611 & 14.0 & 18.0 & $16.0^{\mathrm{aA}}$ & 17.7 & 28.3 & $21.3^{\mathrm{bB}}$ \\
\hline & 655 & 14.0 & 19.6 & $16.6^{\mathrm{aBC}}$ & 17.3 & 24.7 & $20.3^{\mathrm{bA}}$ \\
\hline \multirow{6}{*}{ Wheat } & 311 & 15.0 & 23.3 & $18.1^{\mathrm{aE}}$ & 18.7 & 25.7 & $21.5^{\mathrm{bB}}$ \\
\hline & 380 & 13.0 & 19.0 & $16.0^{\mathrm{aB}}$ & 19.3 & 25.3 & $21.5^{\mathrm{bB}}$ \\
\hline & 478 & 14.3 & 22.7 & $17.3^{\mathrm{aD}}$ & 17.7 & 27.0 & $20.9^{\mathrm{bB}}$ \\
\hline & 554 & 13.3 & 21.3 & $16.1^{\mathrm{aBC}}$ & 16.3 & 24.7 & $19.5^{\mathrm{bA}}$ \\
\hline & 611 & 14.0 & 19.7 & $16.7^{\mathrm{aC}}$ & 19.7 & 27.7 & $22.3^{\mathrm{bC}}$ \\
\hline & 655 & 13.7 & 19.3 & $15.4^{\mathrm{aA}}$ & 20.7 & 33.0 & $24.1^{\mathrm{bD}}$ \\
\hline
\end{tabular}

$\overline{\mathrm{a}, \mathrm{b}}$ Significant differences between the average angle of static friction of cereal kernels on friction plates with identical hardness and different surface orientations are marked with different letters; ${ }^{\mathrm{A}, \mathrm{B}, \mathrm{C}, \mathrm{D}, \mathrm{E}}$ significant differences between the average angle of static friction of cereal kernels on friction plates with an identical surface orientation and different hardness are marked with different letters. higher values of the angle of static friction at the beginning of sliding on a friction plate with a perpendicular surface orientation resulted from differences in deformation force because the remaining components of the friction force were highly similar for both positions of sliding particles. On a friction plate with a perpendicular surface orientation, the perpendicular peaks of macroscopic asperities produce grooves and lead to the abrasion of the contact surface when kernel motion is initiated. In turn, on a friction plate with a parallel surface orientation, kernels slide along asperity peaks, and the resulting surface wear is sustained in continuous lines or stripes. This observation is consistent with the hypothesis formulated by Frączek [1] who argued that the surface asperities of friction plates (characterized by high hardness) do not undergo rapid deformation, which leads to the cutting of kernel surface. Popov [4] analyzed friction pairs characterized by different hardness and observed plastic deformations in the surface microroughness of the softer material across contact area bridges. The structural peaks formed during machining are wider in the perpendicular than the parallel direction; therefore, surface wear is greater in seeds moving on a friction plate with a perpendicular orientation, which increases the angle and coefficient of friction between friction pair components.

The hardness of the friction plate exerted a much smaller effect on the kernels' angle of static friction than its surface orientation. The difference between the largest and the smallest angle of static friction ranged from $1.0^{\circ}$ (oats, perpendicular orientation) to $4.6^{\circ}$ (wheat, perpendicular orientation). Several homogeneous groups with similar angles of static friction on steel plates with a given hardness were identified by ANOVA. Smaller differences in the average angle of static friction were noted in rye and barley kernels on steel plates with a parallel surface orientation and in oat kernels on steel plates with a perpendicular surface orientation. In most cases (4 out of 8 variants), the average angle of static friction was largest on a steel plate with the lowest hardness $(311 \mathrm{HV})$ and (in 2 out of 8 variants) on a steel plate with the hardness of $611 \mathrm{HV}$. The maximum values of the angles of static friction on the above plates should not be directly associated with plate hardness, but with the surface roughness of machined steel. In a study by Kaliniewicz et al. [9], the angle 


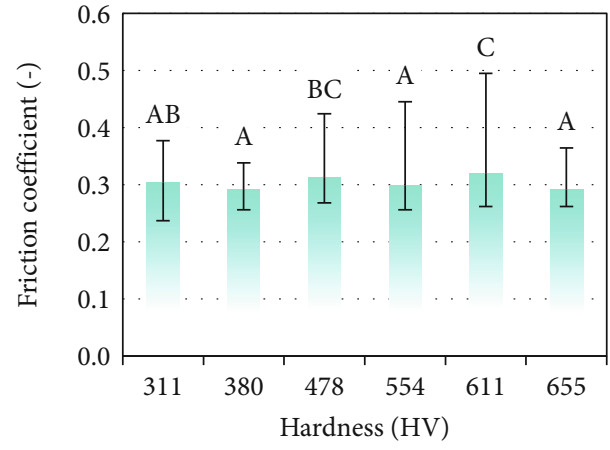

(a)

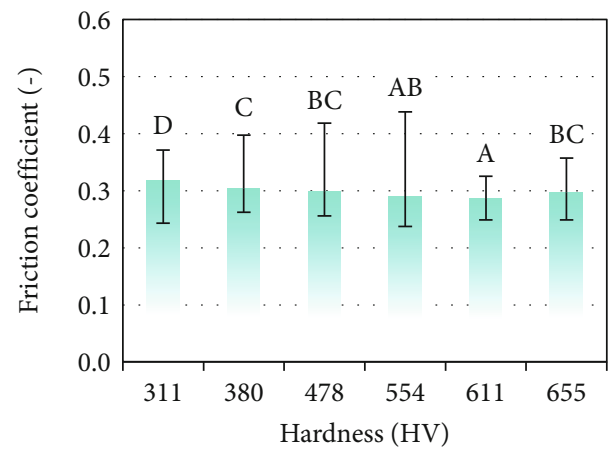

(c)

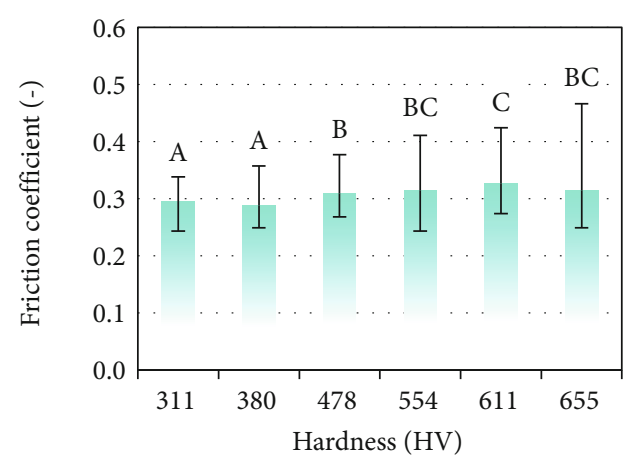

(b)

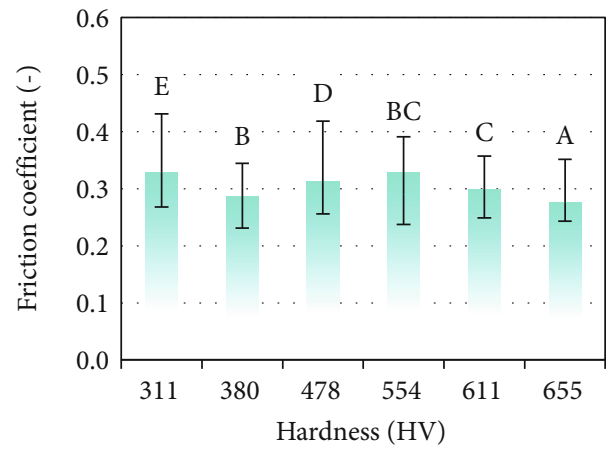

(d)

Figure 5: The coefficient of static friction (mean value and minimum-maximum value) of cereal kernels on friction plates with different hardness and parallel surface orientation: (a) barley; (b) oats; (c) rye; (d) wheat.

of static friction differed by as much as $8^{\circ}$ on friction plates whose surface roughness varied within the same range of values as in the present study. Therefore, it can be assumed that the absence of similar roughness parameters on the surface of the analyzed friction plates hinders the correct interpretation of the correlations between surface hardness and the angle of static friction of kernels. Kaliniewicz et al. [9] did not measure the hardness of the friction plate; therefore, the results cannot be compared with current findings. Nonetheless, changes in friction plate hardness induced far smaller variations in the angle of static friction which did not exceed $4.6^{\circ} \mathrm{C}$. The above implies that friction plate hardness exerts only a minor effect on the frictional properties of grain.

A comparison of the average angles of static friction on different friction plates revealed minor differences in this parameter across the analyzed cereal species, which did not exceed $4^{\circ}$ in the majority of cases. Similar results were reported by Kaliniewicz et al. [9] in a study evaluating the extent to which the surface roughness of a friction plate affects the frictional properties of cereal kernels.

The values of the coefficient of static friction when the analyzed kernels were set into motion on friction plates with different hardness and parallel surface orientation are presented in Figure 5. Several homogeneous groups were identified despite minor differences and overlaps in the average values of the coefficient of static friction. However, uniform change trends could not be determined for all analyzed cereal species. The coefficients of static friction were lowest on friction plates with a hardness of $380 \mathrm{HV}$ (barley and oats),
$611 \mathrm{HV}$ (rye), and $655 \mathrm{HV}$ (wheat), and they were highest on friction plates with a hardness of $611 \mathrm{HV}$ (barley and oats) and $311 \mathrm{HV}$ (rye and wheat).

The values of the coefficient of static friction when the analyzed kernels were set into motion on friction plates with different hardness and perpendicular surface orientation are presented in Figure 6. The influence of plate hardness on the frictional properties of grains differed across the examined cereal species, and the values of the coefficient of static friction were lowest on steel plates with a hardness of around $500 \mathrm{HV}$, which corresponds to friction plate roughness of around $\mathrm{Ra}=2.5 \mu \mathrm{m}$. The lowest values of the coefficient of static friction were reported by Ibrahim [23] for the skin of the Amazon tree boa on surfaces with similar roughness. In contrast, in a study by Kaliniewicz et al. [9], the seeds of the principal cereal species were characterized by the highest values of the coefficient of static friction on plates with an estimated roughness of $\mathrm{Ra}=2.5 \mu \mathrm{m}$.

The average values of the coefficient of static friction of cereal kernels on steel plates with different surface orientations are presented in Figure 7 . The analyzed parameter ranged from 0.299 to 0.412 . The results of the present study indicate that the coefficient of static friction of cereal kernels remains fairly constant at around 0.3 when the friction plate has a parallel surface orientation, and it reaches around 0.4 when the friction plate has a perpendicular surface orientation. The coefficient of static friction remained constant when seeds moved freely on the friction plate, and it decreased when additional normal force (such as the pressure 


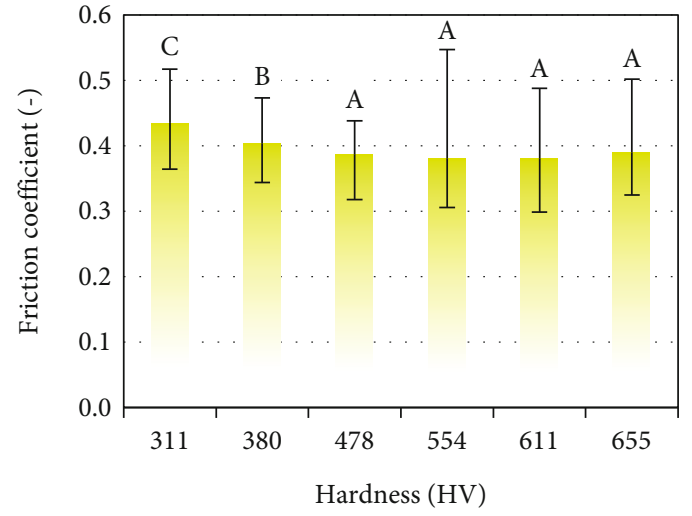

(a)

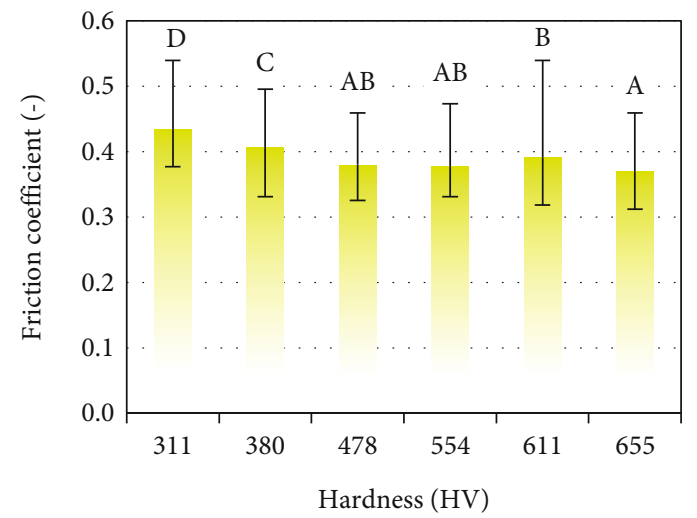

(c)

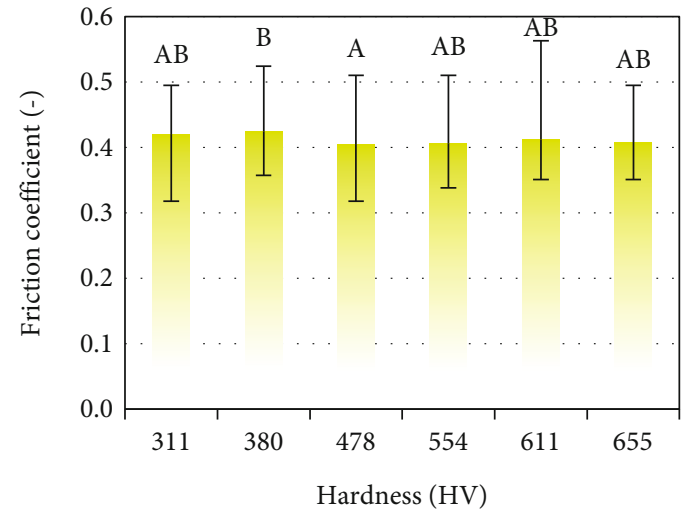

(b)

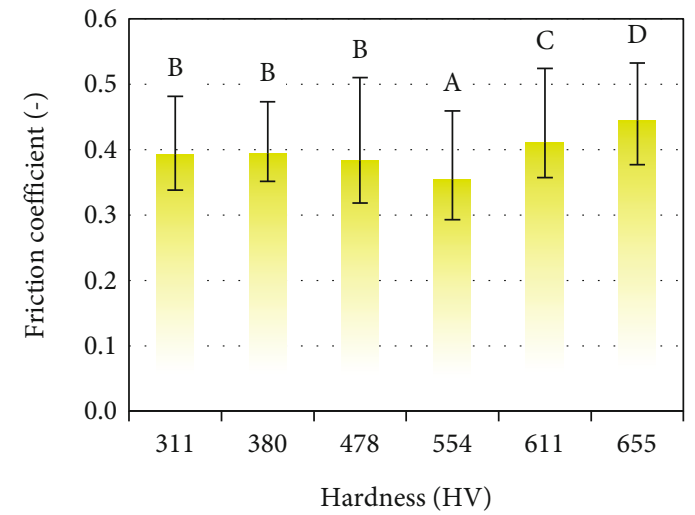

(d)

Figure 6: The coefficient of static friction (mean value and minimum-maximum value) of cereal kernels on friction plates with different hardness and perpendicular surface orientation: (a) barley; (b) oats; (c) rye; (d) wheat.

exerted by a structural element) was applied to the seeds. This decrease can reach even $50 \%$ within the analyzed range of moisture content values $[1,23,24]$, and it is associated with a nonproportional increase in contact stress and a rise in normal pressure [1]. Direction-dependent friction anisotropy was also observed in snake skin $[6,25]$. The frictional behavior of snake skin differs considerably during longitudinal and perpendicular motion, which facilitates legless locomotion. Researchers have attempted to determine the frictional properties of seeds of various cereal species. In most cases, the geometric parameters of the analyzed frictional surfaces (such as concrete, steel, and wood) were not provided; therefore, information was imprecise and inaccurate. However, if the above differences are disregarded, the coefficients of static friction calculated on a steel friction plate in this study are similar to those reported by Molenda and Horabik [5], Sologubik et al. [26], and Kaliniewicz et al. [10]. Similar values of the coefficient of static friction on a steel friction plate have been reported in other plant species, including chick pea seeds [27], corn [28], kidney beans [29], peas [29, 30], coriander [31], cowpeas [32], and flax seeds [33].

\section{Conclusions}

It can be concluded that the surface orientation of a friction plate significantly influences the frictional properties of cereal kernels. Higher values of the angle and coefficient of static friction were noted when kernel motion was initiated on friction plates with perpendicular rather than parallel surface orientation relative to its inclination tilt. The difference in the average angle of static friction of grain on friction plates with perpendicular and parallel surface orientations ranged from around $3^{\circ}$ to around $9^{\circ}$, and significant differences in this parameter were not observed across the analyzed cereal species. The variations in the average angle and coefficient of static friction of kernels with a different position relative to the surface orientation of the friction plate could be attributed to differences in static friction during the initiation of kernel motion. On friction plates with a perpendicular surface orientation, kernel motion is initiated when frictional bonds are broken, which leads to the abrasion of nearly the entire contact surface. In contrast, on friction plates with a parallel surface orientation, the resulting surface damage is sustained in continuous lines or stripes.

The surface orientation of the friction plate exerted a much greater impact on the frictional properties of kernels than plate hardness. On the analyzed friction plates, the angle of static friction of kernels ranged from $1.0^{\circ}$ to $4.6^{\circ}$, and it was influenced by cereal species. The correlations between plate hardness vs. the angle and coefficient of static friction of cereal kernels could not be determined with a high degree of precision because the surface roughness of the analyzed 


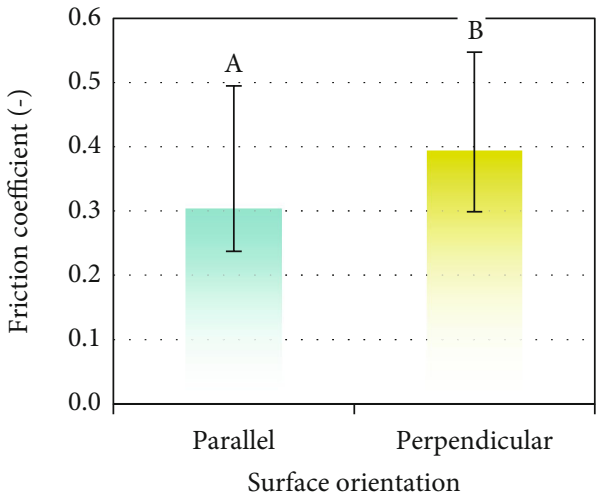

(a)

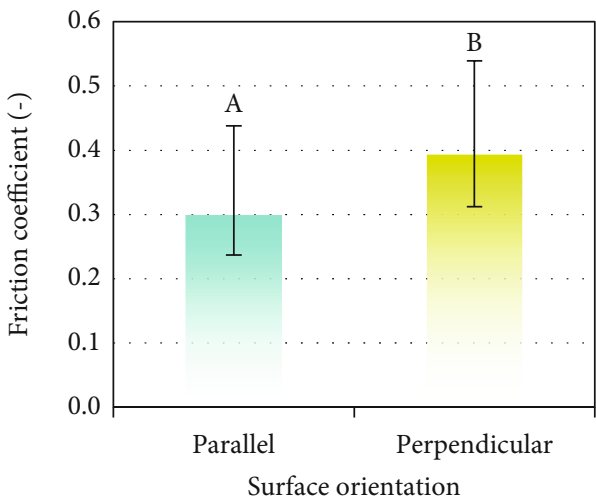

(c)

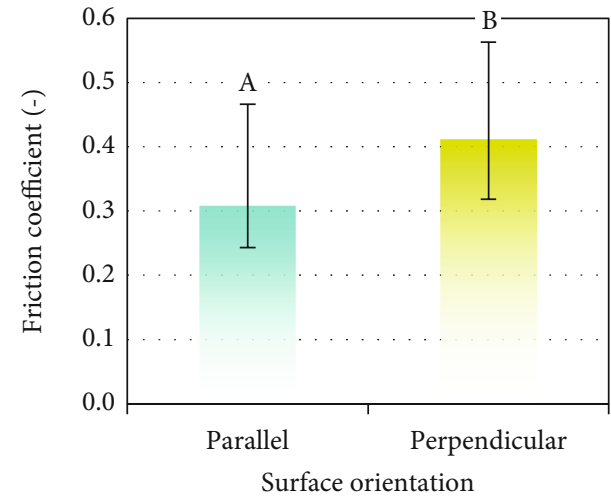

(b)

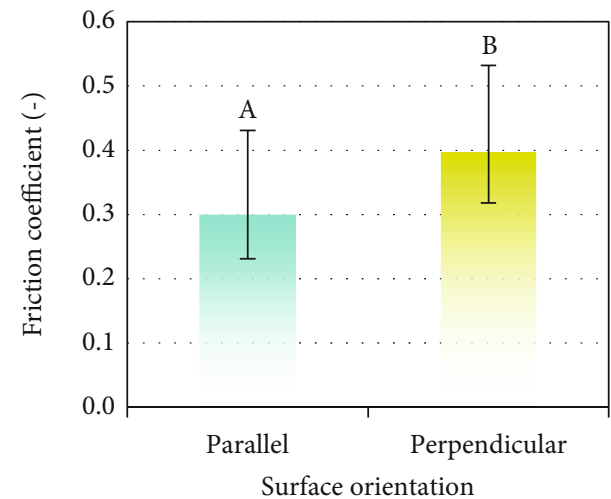

(d)

Figure 7: The coefficient of static friction (mean value and minimum-maximum value) of cereal kernels on friction plates with different surface orientations: (a) barley; (b) oats; (c) rye; (d) wheat.

friction plates varied considerably despite the application of the same processing method and processing parameters. These differences significantly affected the frictional properties of kernels. In general, the coefficient of static friction of the kernels of the analyzed cereal species remained fairly stable within the examined range of plate hardness values, and it was estimated at 0.4 on plates with a perpendicular surface orientation and at 0.3 on plates with a parallel surface orientation.

\section{Data Availability}

The data obtained from the research is reported in Results and Discussion in the form of "tables and figures." If needed, the processed data could be made available upon request.

\section{Conflicts of Interest}

The authors declare that there is no conflict of interest regarding the publication of this paper.

\section{Acknowledgments}

The authors would like to thank Aleksandra Poprawska, MA, for English language editing and proofreading this manuscript. This research was financed by the Ministry of Science and Higher Education of Poland.

\section{References}

[1] J. Frączek, Friction of Granular Materials of Plant Origin (in Polish), Akademia Rolnicza, Cracow, Poland, 1999.

[2] S. Afzalinia and M. Roberge, "Physical and mechanical properties of selected forage materials," Canadian Biosystems Engineering, vol. 49, pp. 2.23-2.279, 2007.

[3] J. Bridwater, "Mixing of powders and granular materials by mechanical means-a perspective," Particuology, vol. 10, no. 4, pp. 397-427, 2012.

[4] V. L. Popov, Contact Mechanics and Friction. Physical Principles and Applications, Springer Nature, Berlin, Germany, 2017.

[5] M. Molenda and J. Horabik, "On applicability of a direct shear test for strength estimation of cereal grain," Particle and Particle Systems Characterization, vol. 21, no. 4, pp. 310-315, 2004.

[6] M. J. Baum, A. E. Kovalev, J. Michels, and S. N. Gorb, “Anisotropic friction of the ventral scales in the snake Lampropeltis getula californiae," Tribology Letters, vol. 54, no. 2, pp. 139150, 2014.

[7] B. Weber, T. Suhina, T. Junge, L. Pastewka, A. M. Brouwer, and D. Bonn, "Molecular probes reveal deviations from Amontons' law in multi-asperity frictional contacts," Nature Communications, vol. 9, no. 1, p. 888, 2018.

[8] Z. Kaliniewicz and Z. Żuk, "A relationship between friction plate roughness and the external friction angle of wheat kernels," International Journal of Food Properties, vol. 20, no. sup3, pp. S2409-S2417, 2017. 
[9] Z. Kaliniewicz, Z. Żuk, and Z. Krzysiak, "influence of steel plate roughness on the frictional properties of cereal kernels," Sustainability, vol. 10, no. 4, p. 1003, 2018.

[10] Z. Kaliniewicz, A. Anders, P. Markowski, K. Jadwisieńczak, and T. Rawa, "Influence of cereal seed orientation on external friction coefficients," Transaction of the ASABE, vol. 59, no. 3, pp. 1073-1081, 2016.

[11] ISO 683-2:2016, Heat-treatable steels, alloy steels and freecutting steels - part 2: alloy steels for quenching and tempering, International Organization for Standardization, Geneva, Switzerland, 2016.

[12] S. P. Metage and J. S. Sidhu, "Optimization of process parameters in induction hardening of $41 \mathrm{Cr} 4$ steel by response surface methodology," International Journal of Mechanical Engineering Research, vol. 7, no. 2, pp. 83-97, 2017.

[13] M. Bayrak, F. Ozturk, M. Demirezen, and Z. Evis, "Analysis of tempering treatment on material properties of DIN 41Cr4 and DIN 42CrMo4 steels," Journal of Materials Engineering and Performance, vol. 16, no. 5, pp. 597-600, 2007.

[14] G. Lesiuk, M. M. Duda, J. Correia, A. M. P. de Jesus, and R. Calçada, "Fatigue crack growth of $42 \mathrm{CrMo} 4$ and $41 \mathrm{Cr} 4$ steels under different heat treatment conditions," International Journal of Structural Integrity, vol. 9, no. 3, pp. 326-336, 2018.

[15] P. Niesłony, K. Żak, and R. Chudy, "Assessment of energy selected parameters stereometry cutting edge of CBN on the shaping surface after turning steel with high hardness," Mechanik, vol. 10, no. 10, pp. 1384-1385, 2016.

[16] A. Kaleta and K. Górnicki, "Safe grain storage - the study of the issue," Agricultural Engineering, vol. 1, no. 99, pp. 137$143,2008$.

[17] C. Yücel, F. S. Baloch, and H. Özkan, "Genetic analysis of some physical properties of bread wheat grain (Triticum aestivum $\mathrm{L}$. em Thell)," Turkish Journal of Agriculture and Forestry, vol. 33, pp. 525-535, 2009.

[18] L. Babić, M. Babić, J. Turan et al., "Physical and stress-strain properties of wheat (Triticum aestivum) kernel," Journal of the Science of Food and Agriculture, vol. 91, no. 7, pp. 12361243, 2011.

[19] F. Kalkan and M. Kara, "Handling, frictional and technological properties of wheat as affected by moisture content and cultivar," Powder Technology, vol. 213, no. 1-3, pp. 116-122, 2011.

[20] K. H. Kim, S. H. Shin, S. Park, J. C. Park, C. S. Kang, and C. S. Park, "Relationship between pre-harvest sprouting and functional markers associated with grain weight, TaSUS2-2B, TaGW2-6A, and TaCWI-A1, in Korean wheat cultivars," $S A B$ RAO Journal of Breeding and Genetics, vol. 46, no. 2, pp. 319328, 2014.

[21] J. B. Królczyk, "Metrological changes in the surface morphology of cereal grains in the mixing process," International Agrophysics, vol. 30, no. 2, pp. 193-202, 2016.

[22] Z. Kaliniewicz, "Analysis of frictional properties of cereal seeds," African Journal of Agricultural Research, vol. 8, no. 45 , pp. 5611-5621, 2013.

[23] M. M. Ibrahim, "Determination of dynamic coefficient of friction for some materials for feed pellet under different values of pressure and temperature," Misr Journal of Agricultural Engineering, vol. 25, no. 4, pp. 1389-1409, 2008.

[24] B. Szot, J. Horabik, and R. Rusin, "Physical properties characteristic of Polish and Canadian lentil seed," International Agrophysics, vol. 17, pp. 123-129, 2003.
[25] R. A. Berthé, G. Westhoff, H. Bleckmann, and S. N. Gorb, "Surface structure and frictional properties of the skin of the Amazon tree boa Corallus hortulanus (Squamata, Boidae)," Journal of Comparative Physiology A, vol. 195, no. 3, pp. 311-318, 2009.

[26] C. A. Sologubik, L. A. Campañone, A. M. Pagano, and M. C. Gely, "Effect of moisture content on some physical properties of barley," Industrial Crops and Products, vol. 43, pp. 762 767, 2013.

[27] M. Konak, K. Çarman, and C. Aydin, "PH-Postharvest Technology," Biosystems Engineering, vol. 82, no. 1, pp. 73-78, 2002.

[28] M. B. Coşkun, İ. Yalçın, and C. Özarslan, "Physical properties of sweet corn seed (Zea mays saccharata Sturt.)," Journal of Food Engineering, vol. 74, no. 4, pp. 523-528, 2006.

[29] E. Altuntas and H. Demirtola, "Effect of moisture content on physical properties of some grain legume seeds," New Zealand Journal of Crop and Horticultural Science, vol. 35, no. 4, pp. 423-433, 2007.

[30] İ. Yalçin, C. Özarslan, and T. Akbaş, "Physical properties of pea (Pisum sativum) seed," Journal of Food Engineering, vol. 79, no. 2, pp. 731-735, 2007.

[31] Y. Coşkuner and E. Karababa, "Physical properties of coriander seeds (Coriandrum sativum L.)," Journal of Food Engineering, vol. 80, no. 2, pp. 408-416, 2007.

[32] O. Kabas, E. Yilmaz, A. Ozmerzi, and İ. Akinci, "Some physical and nutritional properties of cowpea seed (Vigna sinensis L.)," Journal of Food Engineering, vol. 79, no. 4, pp. 1405-1409, 2007.

[33] R. C. Pradhan, V. Meda, S. N. Naik, and L. Tabil, "Physical properties of Canadian grown flaxseed in relation to its processing," International Journal of Food Properties, vol. 13, no. 4, pp. 732-743, 2010. 